\title{
Effects of Cooperative and Individualistic Instructional Strategies On Students Problem Solving Abilities In Secondary School Chemistry In Ilesa, Nigeria.
}

\author{
Dr. K. O. Aluko and Prof. A.S. Olorundare
}

\begin{abstract}
This study investigated the relative effectiveness of cooperative and individualistic instructional strategies on students' problem solving abilities in secondary school chemistry. It made use of a $3 \times 3 \times 2$ quasi-experimental, non-randomized factorial design. Two hundred and fifty (250) Senior Secondary two (SS II) chemistry students were purposively sampled from three public secondary schools in Ilesa Local Government Area of Osun State, Nigeria. Two research instruments: Researcher's Instructional Packages for solving Chemistry Problems (RIP) and Chemistry Performance Test (CPT) were developed, validated and used for the study. The reliability of the Chemistry Performance Test (CPT) was determined and found to be 0.62 using the Pearson Product Moment Correlation formula. Five hypotheses were raised and tested using Analysis of Covariance (ANCOVA). Two experimental groups (Cooperative Instructional group, Individualistic Instructional group) and a control group were used. The results of the analysis showed that there was a significant difference in the performance of chemistry students exposed to cooperative instructional Strategy, individualistic instructional strategy and conventional teaching method. Both the cooperative instructional strategy and individualistic instructional strategy improved the performance of the learners. The cooperative instructional strategy was found to be most effective in enhancing better performance of the learners.
\end{abstract}

\section{Introduction}

The crucial role science plays in the development of any nation has long been recognized. Nigeria was not left out in the raising of the standard of science teaching through curriculum development. In Nigeria, the Science Teachers Association of Nigeria (STAN) and Comparative Education Study and Adaptation Centre (CESAC) have contributed immensely to curricula innovations in science by the development of Nigerian Secondary Schools Science Project (NSSSP). Most of these innovations are based on inquiry-oriented programmes with emphasis on teacher-student interaction without any mention of how students should interact among themselves [i.e. studentstudent interaction], to learn such materials.

Chemistry as a branch of science has attained a secured position in the curriculum of schools, colleges and universities as an essential part of general education for life [Hill, 1988]. Its importance in modern societies is indisputably significant because of its requirement as a pre-requisite to the study of many other courses like medicine, pharmacy, textiles and clothing, biochemistry, microbiology, agriculture, metallurgy and all the fields of engineering (JAMB brochure, 1992-1994). It thus appears that without chemistry, there can hardly he science because, the scientific development of any nation is enhanced by the quality of chemistry education in its schools (Okafor, 1996). It therefore becomes pertinent that performances in chemistry and in science generally should be of high levels. However, this seems not to be the case in Nigeria because students' performances have not been encouraging (Ajeyalemi, 1983; Bojuwoye, 1985; Adeyegbe, 1993). There are several attempts through the use of carefully planned 
instructional strategies amid models to improve the status of chemistry teaching and learning.

Despite all these efforts that have been made over the years to improve the quality of science teaching in our schools, students' performance in chemistry has remained persistently poor at the Senior Secondary Certificate Examination, (SSCE) (see appendix 1; Salami, 1992; Adeyegbe, 1993).

This 'poor' performance was attributed to the ineffective and unproductive strategies used by practicing teachers. The preceding situation has prompted efforts to seek for practically oriented teaching strategies that could improve science performance. It is against this background that the present study focused, among other things, on a determination of the effects of cooperative and individualistic instructional strategies on students' problem solving abilities in Secondary School chemistry.

Cooperative problem-solving as a means of instructional strategy equips students with relevant cooperative skills which enable them to work and solve chemical problem together with minimal efforts of the teacher. Considering therefore, the decline over the years in students' performance in Secondary School chemistry examinations, and the potential, which these strategies could have for improving performance, this study explored the extent to which each of these strategies affected students' learning of quantitative problems in chemistry.

One of the major problems which both the students and teachers of science in secondary schools face is that the final examinations for the WASSCE (West African Senior School Certificate Examinations) and the SSCE (Senior Secondary Certificate Examination) of NECO (National Examination Council) are not based on what content areas have been covered but on what should be covered, as outlined in the syllabi. Therefore, many teachers do sacrifice teaching for understanding of the subject matter in an effort to cover the syllabi in time. The present study has used two instructional strategies: Cooperative and Individualistic, to determine the performance of students in chemistry

\section{Clarification Of Major Terms And Variables}

The following terms or variables have been defined as used in this study:

a. Cooperative Instructional Strategy [CIS]: This is a teaching strategy in which students are divided into groups with students of different levels of ability using a variety of instructional activities to improve their understanding of chemistry. Each member of a group is responsible not only for learning what is taught but also for helping group-mates learn, thus creating an atmosphere of achievement. Members of each group are expected to work together as a group to produce a joint and desired outcome to the presented chemistry problem.

b. Individualistic Instructional Strategy [IIS]: This is a teaching strategy in which an individual student works alone based on his/her ability using a variety of instructional activities to improve his/her understanding of chemistry. This strategy requires each individual to present his/her solution to the chemistry problem without the cooperation or assistance of other classmates.

c. Conventional Teaching method (CTM): In this study, the conventional teaching method refers to a situation where the him/her to learning and solving 
problems. The teacher for guiding regarded as the main source and dispenser of knowledge.

d. Problem Solving Ability: This is a. process by which the learner discovers a combination of previously learned rules that he/she can apply to achieve the solution to a given problem. In this study, problem solving ability is measured by the score obtained by a student in the chemistry performance test given to them before and after treatment.

e. Ability Groupings: This is a student's ability to learner understand and solve chemistry problems. They have been categorized into three main groups:

high scorers, medium scorers and low scorers In the present study high scorers are students whose means score in the chemistry test is in the upper quartile $(25 \%)$ i.e (75-100\%), medium scorers are the students whose mean score in the chemistry test is in the middle $50 \%$ i.e $(50-74 \%)$ while how scorers are students whose mean score in the chemistry test is in the bottom $25 \%$ i.e (0$25 \%)$.

f. Strategy: The overalls approach or plan to be used in accomplishing a set goal; in this study, such a goal is the successful solution to the chemistry problems given.

\section{Research Methodology}

This research is based on a quasi-experimental pretest-post test, non-randomize Non- equivalent control group design as described by Campbell and Stanley [1970]. The tests were given immediately after the experiment. The study population are the Senior Secondary Class 2 students [SS2] in Ilesa East Local Government Area of Osun State. Three Schools were selected using a purposive sampling technique based on the set criteria. These are Obokun High School, Ilesa; Ilesa Grammar School, llesa; and St. Lawrences' Grammar School, llesa

Two research instruments were use to collect data for the study which include; Researcher's instructional packages for solving chemistry problems (RIP) Chemistry Performance Test [CPT]. Each item of the test was constructed to meet both content and task specification set for it, to cater for validity.

\section{Research Hypotheses}

The following hypotheses were generated and tested for the study;

Hol: There is no significant difference in the performance of chemistry students exposed to cooperative instructional strategy, individualistic instructional strategy and conventional teaching method.

Ho2: There is no significant difference in the performance of male and female chemistry students exposed to cooperative instructional strategy.

Ho3: There is no significant difference in the performance of male and female chemistry students exposed to individualistic instructional strategy.

Ho4: There is no significant difference in the performance of high scorers, medium scorers and low scorers in chemistry exposed to cooperative instructional strategy.

Ho5: There is no significant difference in the performance of high scorers, medium scorers and low scorers in chemistry exposed to individualistic instructional strategy. 


\section{Data Analysis And Results}

A summary of the results of the analyses is presented following the sequence in which the hypotheses were tested and reported. All the hypotheses were tested at the 0.05 level of significance.

\section{Hypothesis 1}

There is no significant difference in the performance of chemistry students exposed to cooperative instructional strategy, individualistic instructional strategy and conventional teaching method.

The result of data analysis for testing this hypothesis is shown in Table 1 below.

Table 1-ANCOVA Summary Table on Post test Performance Scores According To Treatment.

\begin{tabular}{|c|c|c|c|c|c|c|}
\hline $\begin{array}{ll}\begin{array}{l}\text { Source } \\
\text { variation }\end{array} & \text { of } \\
\end{array}$ & $\begin{array}{l}\text { Sum of } \\
\text { squares }\end{array}$ & DF & $\begin{array}{l}\text { Mean } \\
\text { Square }\end{array}$ & $\mathbf{F}$ & Sig. of $F$ & Remark \\
\hline Covariates & 415.881 & 1 & 415.881 & 139.022 & .000 & $*$ \\
\hline Pretest & 415.881 & 1 & 415.881 & 139.022 & .000 & $*$ \\
\hline Main Effect & 257.110 & 2 & 128.555 & 42.974 & .000 & $*$ \\
\hline Treatment & 257.110 & 2 & 128.555 & 42.974 & .000 & * \\
\hline Explained & 672.991 & 3 & 224.330 & 74.990 & .000 & * \\
\hline Residual & 735.905 & 246 & 2.991 & & & \\
\hline Total & 140.896 & 249 & 5.658 & & & \\
\hline
\end{tabular}

* Significant at $\mathrm{P}<0.05$

The result in Table 1 has an $\mathrm{F}$ value of 42.974 which is significant at 0.05 level. This is because; the significance of $F$ value of 0.000 is less than $0.05(F=42.974,0.05>$ 0.000). Hence significant different existed as a result of which Null hypothesis was rejected. Treatment had a significant effect on the performance of subjects in chemistry as shown in the Table 1.

\section{Hypothesis 2}

There is no significant difference in the performance of male and female chemistry students exposed to cooperative instructional strategy.

The result of data analysis for testing this hypothesis is shown in Table 2 below.

Table 2 ANCOVA summary Table for Post test Performance Scores According to Gender [Cooperative Instruction Strategy only].

\begin{tabular}{|l|l|l|l|l|l|l|}
\hline $\begin{array}{l}\text { Source of } \\
\text { variation }\end{array}$ & $\begin{array}{l}\text { Sum of } \\
\text { squares }\end{array}$ & DF & Mean Square & F & Sig. of F & Remark \\
\hline Covariates & 179.001 & 1 & 179.001 & 77.150 & .000 & \\
Pretest & 179.001 & 1 & 179.001 & 77.150 & .000 & \\
Main Effects & 1.496 & 1 & 1.496 & .645 & .424 & Not \\
Gender & 1.496 & 1 & 1.496 & .645 & .424 & Significant \\
Explained & 180.497 & 2 & 90.246 & 38.898 & .000 & \\
Residual & 208.815 & 90 & 2.320 & & & \\
Total & 389.312 & 92 & 4.232 & & & \\
& & & & & & \\
\hline
\end{tabular}

The result in Table 2 shows an $\mathrm{F}$ value of 0.645 which was not significant at the 
0.05 level. This was because the significance of $\mathrm{F}$ value of 0.424 is greater than $0.05[\mathrm{~F}=$ $0.645,0.05<0.4241$. Hence, there was no significant difference, as a result of which Null hypothesis was accepted. This means therefore that gender had no significant effect on the performance of subjects in chemistry.

\section{Hypothesis 3}

There is no significant difference in the performance of male and female chemistry students exposed to individualistic instructional strategy.

The result of data analysis of testing this hypothesis is shown in Table 3 below.

Table 3 ANCOVA Summary Table for Post Test Performance Scores According to Gender [Individualistic Instructional Strategy only]

\begin{tabular}{|l|l|l|l|l|l|l|}
\hline $\begin{array}{l}\text { Source of } \\
\text { variation }\end{array}$ & $\begin{array}{l}\text { Sum of } \\
\text { squares }\end{array}$ & DF & $\begin{array}{l}\text { Mean } \\
\text { Square }\end{array}$ & F & Sig. of F & Remark \\
\hline $\begin{array}{l}\text { Covariates } \\
\text { Pretest }\end{array}$ & 89.296 & 1 & 89.296 & 27.460 & .000 & .000 \\
Main Effects & 89.296 & 1 & 89.296 & 27.460 & & \\
Gender & 4.280 & 1 & 4.280 & 1.482 & .227 & .227 \\
& 4.280 & 1 & 4.280 & 1.482 & Not \\
Explained & 94.116 & 2 & 47.058 & 14,471 & .000 & \\
Residual & 260.149 & 80 & 3.252 & & & \\
Total & 354.2655 & 82 & 4.320 & & & \\
\hline
\end{tabular}

The result in Table 3 shows that $\mathrm{P}>0.05$. It has an $\mathrm{F}$ value of 1.482 , which was not significant at the 0.05 level. This was because the significance of $F$ value of 0.227 is greater than $0.05[\mathrm{~F}=1.482,0.05<0.2271$. With this result, there was no significant difference. The Null hypothesis was therefore accepted. This means therefore that gender had no significant effect on the performance of the students in chemistry.

\section{Hypothesis 4}

There is no significant difference in the performance of high scorers, medium scorers and low scorers in chemistry exposed to cooperative instructional strategy.

The result of data analysis for testing this hypothesis is shown in Table 4 below.

Table 4 ANCOVA summary table for the post test performance scores according to high scorers, medium scorers and low scorers [cooperative instructional strategy only].

\begin{tabular}{|l|l|l|l|l|l|l|}
\hline $\begin{array}{l}\text { Source of } \\
\text { variation }\end{array}$ & $\begin{array}{l}\text { Sum of } \\
\text { squares }\end{array}$ & DF & $\begin{array}{l}\text { Mean } \\
\text { Square }\end{array}$ & F & Sig. of F & Remark \\
\hline $\begin{array}{l}\text { Covariates } \\
\text { Pretest }\end{array}$ & 179.001 & 1 & 179.001 & 253.794 & .000 & \\
Main Effects & 179.001 & 1 & 179.001 & 253.794 & .000 & \\
Gender & 147.539 & 2 & 73.769 & 104.593 & .000 & .000 \\
Explained & 147.539 & 2 & 73.769 & 104.593 & Significant \\
Residual & 326.540 & 3 & 108.847 & 154.326 & .000 & \\
Total & 62.772 & 89 & .705 & & & \\
\hline
\end{tabular}


The result in Table 4 has an F' value of 104.593 which is significant at the 0.05 level. This is because the significance of $\mathrm{F}^{\prime}$ value of 0.000 is less than 0.05 [F' $=$ $104.593,0.05>.000]$. The high scorers performed significantly better than the medium scorers while the medium scorers in turn performed significantly better than the low scorers as can be seen from table 5.The Null hypothesis concerning the ability groupings in respect of cooperative instructional strategy can thus be rejected.

\section{Hypothesis 5}

There is no significant difference in performance of high scorers, medium scorers and low scorers in chemistry exposed to individualistic instructional strategy.

The result of data analysis for testing this hypothesis is shown in Table 5 below.

Table 5 ANCOVA summary table for the post test performance scores according to high scorers, medium scorers and low scorers [cooperative instructional strategy only].

\begin{tabular}{|l|l|l|l|l|l|l|}
\hline $\begin{array}{l}\text { Source of } \\
\text { variation }\end{array}$ & $\begin{array}{l}\text { Sum of } \\
\text { squares }\end{array}$ & DF & $\begin{array}{l}\text { Mean } \\
\text { Square }\end{array}$ & F & Sig. of F & Remark \\
\hline Covariates & 89.296 & 1 & 89.296 & 101.266 & .000 & \\
Pretest & 89.296 & 1 & 89.296 & 101.266 & .000 & .000 \\
Main Effects & 195.308 & 2 & 97.654 & $10: 745$ & .000 & Significant \\
Scorers & 195.308 & 2 & 97.654 & $10: 745$ & .000 & \\
Explained & 284.603 & 3 & 94.868 & 107.585 & & \\
Residual & 69.662 & 79 & .882 & & & \\
Total & 354.265 & 82 & 4.320 & & & \\
& & & & & & \\
\hline
\end{tabular}

The result in Table 5 has an $\mathrm{F}$ value of 110.745 , which is significant at the 0.05 level. This is because the significance of $\mathrm{F}$ value of .000 is less than $0.05(\mathrm{~F}=110.745,0.05>0.000)$

The high scorers performed significantly better than the medium scorers and the medium scorers in turn performed significantly better than the low scorers. The Null hypothesis with respect lo ability groupings in respect of individualistic instructional strategy can thus be rejected.

The summary of table 6 indicated that $\mathrm{P}<0.05$. This gives indication that a significant difference actually existed as a result of which null hypothesis was rejected.

\section{Discussion}

This study was undertaken to examine the effects of cooperative and individualistic instructional strategies on the problem solving abilities of students in chemistry. The findings of the study indicated a significant difference among the three modes of instructional strategies [Table $2-6$ ]. The results have shown that chemical problem solving abilities are best enhanced by cooperative learning environment. It was hypothesized that there is no significant difference in the performance of chemistry students exposed to cooperative instructional strategy, individualistic instructional strategy and conventional teaching method. However, the treatment had a significant effect on the performance of subjects in chemistry as shown in Table 2. It was revealed 
that students in the cooperative group performed best followed by the individualistic group and control group respectively. It could be inferred from these findings that the treatment has the tendency of enhancing performance more than the conventional approach would do. This finding supports those of Husband [1940] and Kugman [1944] who claimed that cooperative learning environment favour problem-solving activities. Similarly, Johnson and Johnson, 1978, Nelson and Skon, 1981 concluded that cooperative is more effective than competitive or in individualistic efforts. However, Okebukola and Ogunniyi [1984] found out that competition was more superior to cooperative and individualistic class structures in laboratory work. Alebiosu [19981 investigated the effects of two cooperative learning models [Student Team Achievement Division- STAD and Jigsaw II] on senior secondary school students' cognitive achievement in Chemistry, attitude towards chemistry and achievement in practical skills in chemistry. He found that there were significant main effects of treatment on the achievement of subject in Chemistry.

\section{Conclusion and Recommendation}

The way chemistry is being taught in our secondary school has called for an appraisal because of its importance among other science subjects. The poor performance of learners in the subject also calls for improvement in the teaching and learning of the subject. This has led to the focus of the present Study to find an alternative method apart from the conventional method commonly used by most schools.

The findings of this study have revealed that there was a significant difference in the performance of chemistry students exposed to cooperative instructional strategy, individualistic instructional strategy and conventional teaching method. The cooperative instructional strategy was found to be most effective in enhancing better performance of the learners. There was no significant difference in the performance of male and female chemistry students exposed to cooperative instructional strategy and individualistic instructional strategy. There was significant difference in the performance of high scorers, medium scorers and low scorers in chemistry exposed 1.0 cooperative instructional strategy and individualistic instructional strategy.

Based on the findings from this study, the following recommendations are considered relevant.

1. In order to solve time problem of poor performance of students in chemistry at both internal and external examinations, the current prevailing teaching/learning approach should be restructured so as to give room for new instructional strategies, which will make students good problem-solvers. For instance the usual stereotyped lecture method of teaching chemistry should be discouraged and replaced by cooperative method of teaching.

2. Regular workshops, seminars and symposia on topics/concepts of the chemistry curriculum should be organized from time to time through universities for chemistry teachers in the schools so that they would be exposed to the new strategies of leaching chemistry. In such activities strategies such as cooperative and individualistic could be adopted.

3. The curricula of the institutions where teachers [that is, graduates arid NCE] are being trained should be broad based so as to encompass the different instructional strategies that promote problem-solving. 
4.. The chemistry curriculum in the secondary school should 1)e such that. would enable the teachers identify problems, stimulate students thinking ability, and allow for individual and group approaches to solving chemical problems.

\section{References}

Adeyegbe, S.O. [1993]: The senior secondary school science curriculum and candidates performance. An appeal of the first cycle of operation. Journal of STAN. 28,102-131

Adeyegbe, S. O. [1993]: The senior secondary school science curriculum and candidates performance.

An appraisal of the first cycle of operation. Journal of STAN, Vol 28, numbers $1 \& 2$

NERDC Press, Lagos.

Ajeyalemi, D. [1983]: The teaching of chemistry. An experiences in Nigerian secondary schools. Problems and prospects Journal of STAN 28, 77-85.

Alebiosu, K. A. [1998]: "Effects of two cooperative learning models on senior secondary school students' learning outcomes in chemistry. Unpublished Ph.D Dissertation, University of Ibadan, Ibadan.

Bojuwoye, O. [1985]: Crisis in Science classroom. Poor enrolment of secondary school students, in science subjects and its implications for science teachers Journal of STAN 23 [1\&2] 2 14-220.

Hill J.W. [1988]: Chemistry for changing times 5th Edition, New York Macmillan. Jamb Examination Brochure, 1992-1994.

Johnson, D.W. and Johnson R.T. [1978]: “Cooperative: competitive an Individual learning”

Journal of Research and Development in Education 12 [1] 3-15.

Kugman, F. [19441: Cooperation Versus individual efficiency in problem-solving. Journal of Educational Psychology, 35 [1], 9 1-100.

Nelson, K. and Skon, R. [1981]: The Art of Solving Problems, London, Hieneman. 271- 276.

Okafor, N .P. [1996]: Scientific literacy: A vehicle for national development. A paper presented during the first national conference and congress of the Nigeria Association of Educationist, for National Development [NAEND] 10-17 November.

Okebukola, P.A. [1985]: The relative effectiveness of cooperative and competitive interaction techniques in strengthening students' performance in science classes. Science Education. 69 [4] 50 1-509

Salami, A. (1992). Secondary education programme under the national policy on education. An assessment based on the WAEC senior secondary school certificate examination paper presented at the WAEC monthly seminar 28 August.

Appendix 1 Enrolment and performance pattern in Senior Secondary Certificate Examination (SSCE) Chemistry 1995-2002.

\begin{tabular}{|c|c|c|c|c|c|}
\hline YEAR & $\begin{array}{l}\text { TOTAL } \\
\text { ENTRY }\end{array}$ & TOTAL SAT & $\begin{array}{l}\text { TOTAL } \\
\text { CREDIT 1-6 }\end{array}$ & $\begin{array}{l}\text { TOTAL PASS } \\
7-8\end{array}$ & FAIL F9 \\
\hline 1995 & 170221 & $\begin{array}{l}165665 \\
97.32 \% \\
\end{array}$ & $\begin{array}{l}60063 \\
36.25 \% \\
\end{array}$ & $\begin{array}{l}47593 \\
28.72 \% \\
\end{array}$ & $\begin{array}{l}58009 \\
35.01 \\
\end{array}$ \\
\hline 1996 & 179964 & $\begin{array}{l}176584 \\
98.12 \%\end{array}$ & $\begin{array}{l}53969 \\
30.56 \%\end{array}$ & $\begin{array}{l}43194 \\
24.46 \%\end{array}$ & $\begin{array}{l}62561 \\
35.42 \%\end{array}$ \\
\hline 1997 & 175330 & $\begin{array}{l}172383 \\
98.32 \%\end{array}$ & $\begin{array}{l}40652 \\
23.58 \%\end{array}$ & $\begin{array}{l}34978 \\
20.28 \%\end{array}$ & $\begin{array}{l}96753 \\
56.11 \%\end{array}$ \\
\hline 1998 & 185430 & $\begin{array}{l}182659 \\
98.50 \%\end{array}$ & $\begin{array}{l}39085 \\
21.39 \%\end{array}$ & $\begin{array}{l}40651 \\
22.25 \%\end{array}$ & $\begin{array}{l}95498 \\
52.28 \%\end{array}$ \\
\hline 1999 & 227696 & $\begin{array}{l}223307 \\
98.07 \%\end{array}$ & $\begin{array}{l}69411 \\
31.08 \%\end{array}$ & $\begin{array}{l}51665 \\
23.13 \%\end{array}$ & $\begin{array}{l}94347 \\
42.24 \%\end{array}$ \\
\hline 2000 & 165461 & $\begin{array}{l}160933 \\
97.26 \%\end{array}$ & $\begin{array}{l}51534 \\
32.03 \%\end{array}$ & $\begin{array}{l}43316 \\
26.91 \%\end{array}$ & $\begin{array}{l}66083 \\
41.06 \%\end{array}$ \\
\hline 2001 & 311606 & $\begin{array}{l}301740 \\
96.83 \%\end{array}$ & $\begin{array}{l}109397 \\
36.25 \%\end{array}$ & $\begin{array}{l}81679 \\
27.06 \%\end{array}$ & $\begin{array}{l}110664 \\
36.67 \%\end{array}$ \\
\hline
\end{tabular}

